\title{
PENERAPAN PENYEMBUHAN BAGI PECANDU NARKOBA DENGAN MEMBANGKITKAN KESADARAN AGAMA MELALUI PEMBETULAN NILAI PENDIDIKAN IBADAH, AKIDAH, DAN AKHLAK DI YAYASAN REHABILITASI RUMAH UMMI SUNGGAL
}

\author{
Nelvitia Purba ${ }^{1)}$, Sri Sulistyawati ${ }^{2)}$, Ahmad Darwis $^{3)}$ \\ UMN Al Washliyah Medan ${ }^{1)}$ \\ UMN Al Washliyah Medan ${ }^{2)}$ \\ UMN Al Washliyah Medan ${ }^{3)}$ \\ nelvitiapurbaumn@gmail.com
}

\begin{abstract}
ABSTRAK
Kejahatan penyalahgunaan Narkotika merupakan kategori sebuah tindak kejahatan yang luar biasa (extraordinary crime) ,oleh karena itu perlu ditangani secara intensif. Strategi pemberantasan Penyalahgunaan Narkotika ini terdapat tiga unsur yang utama antara lain :Pencegahan, Penindakan dan Peran Masyarakat.Rehabilitasi terhadap penyalahgunaan Narkotika merupakan suatu tindakan penyembuhan terhadap eks narkoba salahsatu program yang dijalankan melalui pemdekatan Agama melalui pembetulan nilai pendidikan Ibadah, Akhlak dan Akidah.Metode Pelaksanaan Kegiatan Rehabilitasi di "RUMAH UMMI" ini rutin dilakukan kegiatan intensif rutin keagamaan setiap Minggu pada Hari Rabu dan Kamis.Melalui kegiatan Abdimas ini maka Tim Pengabdian UMN Al Washliyah Medan melaksanakan kegiatan ini disamping kegiatan Ceramah Agama dilanjutkan kepada Kegiatan Praktek Ibadah kepada setiap orang yang direhabilitasi tersebut secara bergilir.Hasil dari Kegiatan Pengabdian Kepada Masyarakat ini setelah menjalani rehabilitasi di Rumah Ummi ini eks Narkoba menjadi muslim yang taat beribadah dan memiliki karakter yang baik di dalam menjalankan aktivitasnya sehari hari di dalam lingkungan keluarga dan masyarakat serta tidak akan kembali lagi mengkomsumsi barang haram tersebut.
\end{abstract}

Kata Kunci : Terapi, Pendekatan Agama, Karakter yang baik, Ceramah dan Praktek

\section{ABSTRACT}

Narcotics abuse crime is a category of extraordinary crimes, therefore it needs to be dealt with intensively. The strategy to eradicate Narcotics Abuse consists of three main elements, among others: Prevention, Enforcement and the Role of the Community. Rehabilitation activities at "UMMI HOUSE" are routinely carried out by intensive religious routine activities every Sunday on Wednesday and Thursday. Through this Abdimas activity, the UMN Al Washliyah Service Team in Medan carried out these activities in addition to the Religious Lecture activities continued to the Religious Practices Activities for each person rehabilitated The results of this Community Service Activities after undergoing rehabilitation at this Ummi House ex-Narcotics became devout Muslims and have good character in carrying out their daily activities in the family and community environment and will not return to consume these illicit goods.

Keywords: Therapy, Religious Approach, Good Character, Lecture, and Practice

\section{PENDAHULUAN}

Pada masa sekarang ini dengan kemajuan teknologi dan ilmu pengetahuan Penyalahgunaan Narkotika di kalangan remaja merupakan trend pergaulan remaja, BNN menyebut pengguna Narkoba di Indonesia mencapai 5.1 juta orang dan terbesar di Asia Tenggara dan jumlah tersebut $40 \%$ diantaranya berasal pelajar dan mahasiswa [1]
Sumatera Utara berada sekitar 2,2 persen dari 262 juta pengguna Narkoba. Pada Tahun 2016 terdapat 5,9 juta Anak menjadi pecandu narkoba. Dalam sehari ada 37 hingga 40 orang meninggal siasia karena penyakit yang ditimbulkan oleh Narkoba. Sasaran yang paling daerah transit yang paling banyak adalah Sumatera Utara karena banyaknya pelabuhan ilegal dan juga 
pengawasan di garis pantai kita yang relatif lemah. Propinsi Sumatera Utara merupakan salah satu daerah yang dekat dengan Malaysia karena narkoba tersebut mayoritas berasal dari luar negeri ..2] Masa modren saat ini dengan mudahnya untuk mendapatkan barang haram tersebut dari oknum-oknum yang tak bertanggung jawab [3] Bahkan mudah untuk menemukan narkoba khususnya golongan I seperti shabu, heroin, ganja atau ektasi karena bisa diperoleh melalui pelayanan kefarmasian. Obat-obatan tersebut kerap digunakan untuk campuran minuman enegy drink dan dimasukkan ke dalam makanan atau minuman ringan (snack) anak - anak sekolah [4]

Sesuai dengan PP No 25 Tahun 2011 dan Inpres No.6/2018 Tentang Rencana Aksi Nasional Pencegahan Dan Penyalahgunaan Narkotika Dan Peredaran Gelap Narkotika Prekursor Narkotika Tahun 2018 - 2019 merupakan Program dari Pemerintah yang harus didukung oleh semua pihak. Oleh karena itu bagi pecandu - pecandu narkoba tersebut yang pada umumnya dikalangan remaja dan usia sekolah perlu dilakukan rehabilitasi. Dalam proses Rehabilitasi tersebut dalam penyembuhan sangat tergantung dari pecandu tersebut untuk benar benar untuk tidak menggunakan barang haram tersebut lagi. Rehabilitasi yang dilakukan bagi pecandu narkoba tersebut berdasarkan Undang - Undang Nomor 39 Tahun 2009 terdiri dari dua bagian yaitu : Rehabilitasi Medis dan Rehabilitasi sosial.

Pada rehabilitasi sosial ini kegiatan pemulihan secara fisik, mental maupun sosial dapat dilakukan salah satunya melalui pendekatan agama. Konsep pendekatan agama[5] dalam proses rehabilitasi ini salah satu konsep agama Islam yang dilakukan melalui Pendidikan Nilai Akhlak, Ibadah dan Akidah [6] konsep ini dilakukan satu satunya yang ada di Kota Medan yaitu Yayasan Rehabilitasi "RUMAH UMMI" di Sunggal yang menerapkan Rehabilitasi berlandaskan kepada konsep Agama.

Pendekatan spiritual ini adalah merupakan secara Islam ini adalah sebagai proses pengobatan dan penyembuhan terhadap penyakit mental, spiritual dan moral dan fisik dari korban penyalahgunaan narkotika ini melalui bimbingan dan tuntunan dari Allah SWT, Nabi dan Rasul [7] oleh karena itu sudah terbukti bisa menyembuhkan para pecandu narkoba hal ini berdasarkan wawancara dengan pengurus di Yayasan Rehabilitasi Rumah Ummi Sunggal bahwa pecandu narkoba yang telah direhabilitasi disini tidak kembali lagi sudah bisa beraktivitas seperti sediakala dan tidak menggunakan kembali barang haram tersebut.

Dengan menggunakan Metode ini terbukti juga berhasil menyembuhkan bagi eks narkoba dibuktikan juga di Badan Narkotika Nasional Banda Aceh menunjukkan bahwa Pasien Pecandu Narkoba di Badan Narkotika Aceh terdapat salah satu bangsal yang dalam penanganan penderita narkoba menggunakan sistem psikologi keagamaan melalui kegiatan spiritual di antaranya adalah pengajian, doa dan zikir dan sholat di mesjid.

Semenjak diberlakukan penanganan pasien memalui keagamaan bahwa rata rata $40-60$ pasien mengalami kesembuhan sehingga dapat berinteraksi dengan 
masyarakat dan lingkungan sekitarnya tersebut [8] Pengaturan Rehabilitasi terhadap pecandu narkoba hal ini menunjukkan bahwa kebijakan hukum pidana yang bertujuan agar penyalahguna dan pecandu narkoba tidak lagi menyalahgunakan narkoba.[9]

\section{METODE PELAKSANAAN}

Di dalam melaksanakan Kegiatan Pengabdian Masyarakat ini dilakukan oleh Tim dari UMN Al Washliyah Medan. Pada Tahap Awal mendiskusikan waktu yang telah disepakati dengan Pengurus /Pengelola Rehabilitasi Rumah UMMI ini sehingga tidak menganggu jadwal kegiatan yang rutin setiap hari dilaksanakan.

Setiap hari di mulai bangun pagi, para residen/client wajib melaksanakan sholat subuh berjamaah. Kemudian mandi mempersiapkan diri untuk sarapan pagi. Terus mengikuti program hingga di tutup (closing) pada jam 10 malam. Tidak ada waktu yang tersisa, semua waktu di manfaatkan dalam rangka pemulihan untuk penyembuhan eks narkoba tersebut.Kegiatan Rutin yang berkaitan dengan Keagamaan rutin dilakanakan setiap hari Rabu dan Kamis dengan mendatangkan Ustad.Adapun Metode Kegiatan yang dilaksanakan oleh Tim Pengabdian Masyarakat dari UMN Al Washliyah Medan setiap Hari Selasa rutin dilaksanakan selama satu Bulan dengan kegiatan Ceramah Agama dan Dilanjutkan dengan kegiatan Praktek Ibadah.

\section{PEMBAHASAN}

Kejahatan penyalahgunaan Narkoba adalah merupakan penggunaan Narkoba yang dilakukan dengan maksud tidak untuk pengobatan, melainkan ingin menikmati pengaruhnya, dalam jumlah yang berlebihan yang secara kurang teratur, dan berlangsung cukup lama sehingga menyebabkan terganggunya kesehatan fisik, mental dan kehidupan sosial bagi yang menggunakannya [10]

Yayasan Rehabilitasi Narkoba Rumah Ummi ini Sejak berdiri sejak tanggal 01 Mei 2015 di Medan, berbagai kegiatan dilakukan dalam upaya pemulihan bagi para pecandu narkoba. Pusat rehabilitasi narkoba yang beralamat di Jl. Rajawali no 91 Medan ni, telah terdaftar di Kemenkumham RI No. AHU0007286.AH.01.04 Tahun 2015, Dinas Sosial Tenaga Kerja No. 433.3./3140/DSTKM/2015 dengan Akte Notaris 01 tanggal 09 Mei 2015 Notaris Fenty Iska, SH di Medan.

Pendirian Yayasan ini berawal daripada rendahnya kepedulian umat Islam pada korban penyalahgunaan narkoba dari 20 tempat rehabilitasi yang layak di Sumatera Utara $99 \%$ kepemilikannya adalah merupakan non Muslim.Padahal $90 \%$ korban dari penyalahgunaan narkoba tersebut adalah beragama Islam. Kondisi ini dikhawatirkan akan berpengaruh pada Agama dan akidah keIslaman daripada korban Narkoba.

Yayasan Rehabilitasi Narkoba Rumah Ummi ini bertujuan melakukan kegiatan rehabilitasi serta memperbaiki mental penyalahgunaan narkoba sehingga dapat bermanfaat dan di terima masyarakat luas.

Visi Yayasan Rehabilitasi Narkoba Rumah Ummi yaitu menjadikan para pecandu narkoba agar dapat pulih dan diterima kembali di tengah masyarakat dan dapat beraktivitas dan mengembangkan bakat dan 
kreativitasnya . Sementara misi Yayasan ini adalah memberikan pelayanan dan kenyamanan yang terbaik dengan fasilitas pendukung, dan membangun kembali kepercayaan diri para pelaku penyalahgunaan narkoba melalui program-program pembelajaran dengan adopsi dari program Therapeutic Community (TC), Religis dan dukungan program pelatihan lainnya.

Dalam kegiatan sehari - hari ditekankan kepada aspek pelaksanaan dan pengalaman keagamaan agar memperkuat benteng rohaniah para eks narkoba untuk memenuhi wawasan dan khazanah residen/client sehingga mereka dapat menggunakan potensi rasa dan fikirnya untuk menganalisis setiap persoalan, terutama aspek penyalahgunaan narkoba. Adapun kegiatan rutin keagamaan yang dilakukan di Yayasan Rehabilitasi Rumah UMMI ini. Kegiatan dari Pengabdian Kepada Masyarakat yang dilakukan oleh Tim dari UMN Al Washliyah Medan melalui Kegiatan Ceramah dan Praktek Ibadah.

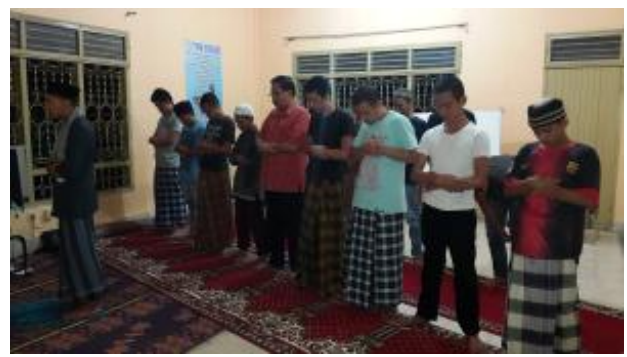

Gambar 1. Kegiatan Sholat

Berjamaah

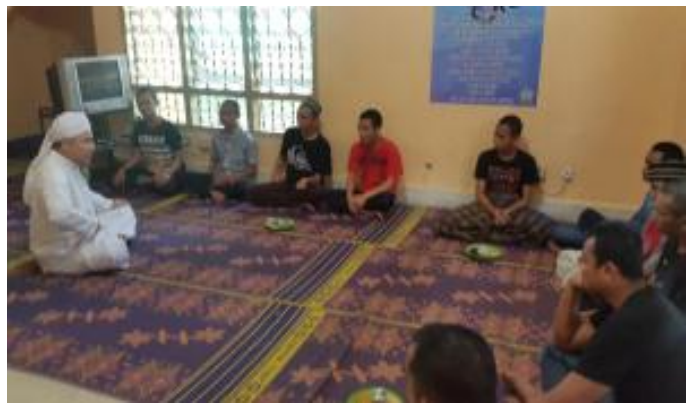

Gambar 2. Kegiatan Ceramah

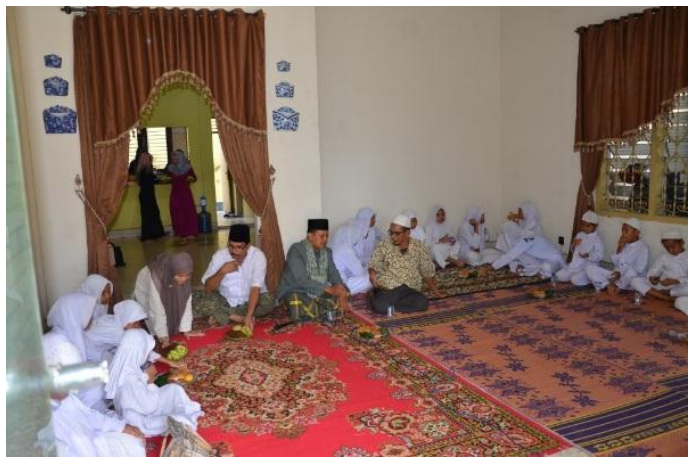

Gambar 3. Kegiatan Makan

Bersama

Kegiatan

Pengabdian Masyarakat dari UMN Alwashliyah ini yang merupakan pendanaanmya berasal dari Dikti bermitra dengan Pusat Rehabilitasi Rumah Ummi ini mengembangkan

Membangkitkan Konsep Beragama dari eks Narkoba.

Kesadaran adalah kondisi tau, mau dan mengerti dengan dirinya sendiri. Kesadaran merupakan pemahaman secara utuh mengenai jati diri yang memberikan ruang seluas-luasnya untuk bertindak dan berperilaku sejalan dengan kemampuan dan batas-batasan yang melekat dalam diri seseorang. Salah satu bentuk kesadaran tersebut adalah dalam kaitanya dengan kesadaran beragama suatu kondisi yang mengerti, memahami, menghayati, dan melaksanakan seluruh ajaran agama secara benar 
dan konsisten di dalam aktivitasnya sehari-hari.

Membangkitkan Kesadaran Beragama adalah merupakan suatu proses daripada akumulasi daripada seluruh pengalaman hidup yang dikenali sebagai refleksi dari falsafah dan pandangan hidup, sehingga menghadirkan nilai-nilai yang positif.Nashori menyebutkan bahwa kondisi sadar sebagai proses pendewasaan hasil dari perkembangan watak keberagamaan dan dilanjutkan sebagai perjalanan spiritual \{11].

Oleh karena konsep dari Yayasan Rumah Ummi sudah merupakan konsep kesadaran Beragama yang selama ini telah mengembangkan konsep spiritual di dalam agenda rutin rehabilitasinya .kegiataan ini hanya melengkapi dari Program yang telah ada sebelumnya diantaranya : a.Belajar Praktek Sholat b.Mengadakan Seminar Kecil dan diskusi yang berkaitan dengan Tema yang aktual yang berkaitan dengan kegiatan-kegiatan keagamaan dsb.

\section{KESIMPULAN}

Bentuk Kegiatan dari Pengabdian Kepada Masyarakat yang dilakukan oleh Tim Dosen Dari UMN Al Washliyah ini adalah melengkapi dari kegiatan - kegiatan rutin keagamaan yang dilakukan setiap harinya oleh para eks narkoba di Rehabilitasi di Yayasan Rumah Ummi Sunggal. Setiap hari wajib sholat berjamaah Sholat Lima Waktu, Hari Rabu Dan Kamis mendatangkan Ustad untuk kegiatan keagamaan. Bentuk Kegiatan Pengabdian Kepada Masyarakat Membangkitkan Kesadaran Beragama yang dilakukan tersebut Antara lain kegiatan Keagamaan
Yang dilakukan adalah : Pembetulan Nilai Ibadah dengan Praktek Sholat yang dilakukan apakah sudah sesuai, Pembetulan Nilai Akidah dan Pembetulan Akhlak dan dilengkapi dengan Ceramah dan Diskusi yang berkaitan dengan masalah-masalah keagamaan yang aktual.

\section{UCAPAN TERIMA KASIH}

Kegiatan Pengabdian Kepada Masyarakat ini Merupakan Tim Dari Dosen-Dosen UMN Al - Washliyah Medan Mengucapkan Terima Kasih Yang sebesar-Besarnya Kepada KemenristekDikti Yang Telah memberikan Bantuan Dana Hibah Program Kemitraan Masyarakat Stimulus (PKMS) Tahun Anggaran 2019.Semoga Dengan Adanya Kegiatan ini sangat bermanfaat bagi Dosen=Dosen UMN Al Washliyah Medan untuk mengaplikasi ilmunya dan Kepada Yayasan Rehabilitasi Rumah UMMI yang terletak di Jalan Rajawali No.91 Sei Sikambing Kecamatan Medan Sunggal Sumatera Utara. mengucapkan terima kasih yang sebesar-besarnya yang bersedia menjadi Mitra sehingga terlaksananya kegiatan Pengabdian Kepada Masyarakat ini.

\section{REFERENSI}

Arman,Narkoba Perang Zaman Now di Medan, 11 Mei 2018

Sri Rahayu dkk,Penyuluhan Pencegahan Penyalahgunaan Narkotika Di Kalangan Mahasiswa, Jurnal Pengabdian Masyarakat, Volume 29 Nomor 4 Agustus - Desember 2014

Evelyn Felicia, Kendala Dan Upaya Rehabilitasi Bagi Pecandu Narkotika Oleh Badan 
Narkotika Nasional Propinsi (BNNP) Yogyakarta e jurnal /uay.ac.id.>articlePDF

Ahmad Saefulloh, Rehabilitasi Eks Pecandu Narkoba Melalui Pendekatan Agama Islam,journal.staincurup.ac.id .pdf PDF.

Muhtar, Pendekatan Sipiritual Dalam Rehabilitasi Sosial

Penyalahgunaan Narkoba Di Pesantren Inabah

Surabaya,journal

Nurdin Bakri,Barmawi, Efektivitas Rehabilitasi Pecandu Narkoba Melalui Terapi Islami Di Badan Narkotika Nasional Aceh, Jurnal PsikoIsmedia, Volume 2 Nomor 1, April 2017.

Dina Novitasari, Rehabilitasi Terhadap Anak Korban Korban Penyalahgunaan
Narkoba,Jurnal Hukum Khaira Ummah Vo.12 No.4 Desember 2017

M.Irfangi, Implementasi Pendekatan Religius Dalam Rehabilitasi

Korban Penyalahgunaan

Narkoba Di Rumah Sakit Khusus Jiwa H.Mustajabah Purbalingga,Jurnal

Kependidikan ,Vol III No.2 November 2015.

Hasyim Hasanah, Faktor-Faktor Pembentuk Kesadaran Beragama Anak Jalanan, SAWWA - Volume 10 Nomor 2 April 2015.

$1.40 \%$ Pengguna Narkoba Pelajar Dan Mahasiswa, https//nasional.sindonews.co m.Diakses Pada Tanggal 23 Mei 2019

4.https/www.republika.co.id Diakses Pada Tanggal 4 Agustus 2019 